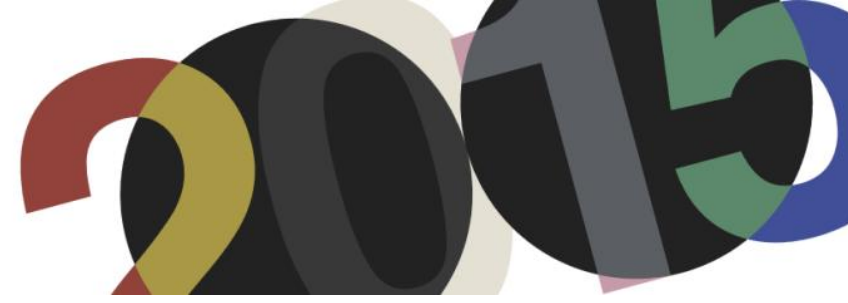

DOI: http://dx.doi.org/10.4995/LC2015.2015.569

\title{
Sobre una caracterización 'corbuseriana' del mobiliario moderno
}

\author{
M. Villanueva Fernández, H. García-Diego Villarías \\ Escuela de Arquitectura, Universidad de Navarra
}

\begin{abstract}
Resumen: A partir de 1920 Le Corbusier comenzó a elaborar un cuerpo teórico sobre el diseño de objetos que iría difundiendo a través de sus escritos y conferencias. Libros como Vers une architecture, L'art décoratif d'aujourd'hui o Précisions sur un état présent de l'architecture et de l'urbanisme han constituído un rico legado de ideas e imágenes interrelacionadas que permiten analizar la propuesta del arquitecto desde el plano de la teoría. Sin embargo, el poder de sus postulados fue continuamente experimentado y corroborado por su obra en materia de mobiliario, hasta el punto de establecerse relaciones directas entre teoría y obra. Esta evolución conjunta proporciona una completa visión del concepto de mobiliario moderno desarrollado por Le Corbusier. Por tanto, esta investigación persigue, por un lado, sacar a la luz un verdadero cuerpo teórico de cuño 'corbuseriano' y específico del equipamiento moderno, haciendo especial mención a los postulados y dibujos originales del arquitecto y, por otro, comprobar la correspondencia real entre sus teorías y sus obras mediante el análisis de una escogida selección de obras del arquitecto pertenecientes al periodo de entreguerras, para, finalmente, ofrecer una caracterización 'corbuseriana' del mobiliario moderno.
\end{abstract}

Abstract: From 1920 Le Corbusier began to develop a theoretical body on the objects design that went spreading through his writings and lectures. Books like Vers une architecture, L'art décoratif d'aujourd'hui or Précisions sur un état présent de l'architecture et de l'urbanisme have constituted a rich legacy of interlinked ideas and images to analyze the proposal of the architect from the level of theory. However, the power of its principles was continuously experienced and corroborated by his work in furniture, to the point of establishing direct relations between theory and work. This joint development provides a comprehensive overview of modern furniture concept developed by Le Corbusier. Therefore, this research aims on the one hand, to expose a 'Corbusian' and specific theoretical body of modern equipment, with special reference to the principles and original drawings by the architect; and, secondly, to check the real correspondence between his theories and works by analyzing a choice selection of works by the architect belonging to the interwar period, to finally offer a 'Corbusian' characterization of modern furniture.

Palabras clave: Teoría; mobiliario; moderno; escritos.

Keywords: Theory; furniture; modern; writings.

\section{Escritos, conferencias y mobiliario}

Le Corbusier dejó tras su muerte en 1965 un rico legado teórico que abarcó desde el urbanismo a gran escala hasta el diseño de objetos. Aunque su interés por este último campo comenzó en su periodo de formación en La Chaux-de-Fonds ${ }^{1}$, no fue hasta la década de 1920, en París, cuando formuló las ideas que fundamentaron la base de su teoría sobre el mueble moderno. Estos principios fueron difundidos no solo a través de su labor como arquitecto, sino también, y de manera más intensa, mediante su obra escrita y divulgación oral, lo que ha

\footnotetext{
${ }^{1}$ En 1912 Le Corbusier escribió Étude sur le mouvement d'art décoratif en Allemagne, resultante del estudio que la Escuela de Artes Aplicadas de La Chaux-de-Fonds le propuso realizar sobre las artes aplicadas en el país germano. Se trataba de su primer libro y el último que escribía en la ciudad suiza, ya que su posterior obra, Aprés le cubisme (1918), fue publicada junto con el pintor Amédée Ozenfant, ya en París, lugar donde estableció su residencia permanente.
} 
permitido profundizar en el pensamiento de Le Corbusier sobre la verdadera caracterización del mobiliario entendido moderno.

Ya en París, el maestro suizo difundió sus ideas sobre los objetos de uso a través de la conocida revista $L^{\prime} E s p r i t$ Nouveau, creada en 1920 por el pintor Amédée Ozenfant, el poeta Paul Dermée y el propio Le Corbusier, y que daría origen a otras conocidas publicaciones ${ }^{2}$. Entre ellas se encontraba Vers une architecture, publicada en 1923 como resultado de compendiar algunos de los artículos más destacados de la célebre revista. Aunque eran escasas las líneas dedicadas al estudio del mobiliario en este libro, el arquitecto presentó el germen de las ideas que se desarrollarían en textos posteriores.

Dos años después, con motivo de la Exposición de Artes Decorativas de París, Le Corbusier publicó L'art décoratif d'aujour'hui, un texto que, además de recoger algunas de las ideas que dieron forma al Pabellón de L'Esprit Nouveau, constituyó una suerte de manifiesto sobre el concepto de bienes útiles modernos y una de las piezas principales que sustentan el cuerpo de su teoría, abordando cuestiones como el ornamento, la belleza, la norma, la función, la máquina, el standard y el mueble moderno.

Estas ideas también fueron difundidas en algunas de sus ilustres conferencias, como la celebrada en Madrid en 1928 Arquitectura, mobiliario y obras de arte, o las llevadas a cabo un año después en Latinoamérica y que darían lugar en 1930 a la publicación Précisions sur un état présent de l'architecture et de l'urbanisme. Justamente, este texto incluía un capítulo, "La aventura del mobiliario", que confirmaba y complementaba las ideas publicadas con anterioridad, centrándose especialmente en la modulación y fabricación industrial de los objetos, así como en su utilización y su relación con el espacio.

En las reflexiones de Le Corbusier difundidas desde 1923 hasta 1930 es posible apreciar un intenso trabajo intelectual que se va puliendo y que en tan sólo siete años expone una clara postulación teórica sobre los objetos de uso, desde el inicio de sus primeras intuiciones hasta su maduración y posteriormente confirmación de sus ideas. No obstante, esa evolución no sólo se produce en el plano teórico sino también, y de forma paralela, en sus obras — desde el diseño del Pabellón de L'Esprit Nouveau hasta la creación de prototipos en 1928, producidos por Thonet en 1930 - que muestran un desarrollo considerable en la praxis llevada a cabo en el campo del diseño por el arquitecto suizo.

Todo este legado ha sido estudiado en profundidad por distintos investigadores a lo largo de la segunda mitad del siglo XX y comienzos del XXI. Entre ellos destaca Arthur Rüegg por la realización de una exhaustiva investigación que ha dado lugar al libro Le Corbusier: Meubles et Intérieurs 1905-1965. Sus aportaciones, junto con las de otros críticos como Banham, Frampton, Cohen, Von Moos o McLeod, y los escritos originales de Le Corbusier han constituido la fuente principal de esta investigación que pretende ofrecer una caracterización 'corbuseriana' del mobiliario moderno.

\section{Apuntes sobre una teoría del mueble moderno}

En 1923, con el libro Vers une architecture, Le Corbusier exponía buena parte del discurso en torno al cual iba a girar el conjunto de su obra. Por un lado, explicaba la necesidad de satisfacer las exigencias funcionales a través

\footnotetext{
${ }^{2}$ Cfr. Cohen, Jean-Louis: Le Corbusier 1887-1965. El lirismo de la arquitectura en la era mecánica. Köln: Taschen, 2004.
} 
de una forma empírica; y por otro, abogaba por la utilización de elementos abstractos para fascinar sensorialmente y fomentar la capacidad intelectual. En el capítulo “Ojos que no ven...”, Le Corbusier abordó cuestiones sobre el mobiliario de la casa y los aspectos funcionales y estéticos de la arquitectura que más tarde, junto con otros conceptos como la proporción o la producción en serie de viviendas, presentadas en "Pura creación del espíritu" y "Casas en serie", se convertirían en un anticipo de la teoría acerca de los objetos de uso que desarrollaría Le Corbusier en 1925 en L'art décoratif d'aujourd'hui.

\subsection{Arte decorativo de 'hoy'}

Precisamente, este libro fue publicado como respuesta al desconcertante panorama de las artes decorativas de la época, y junto con el Pabellón de L’Esprit Nouveau de la Exposición de Artes Decorativas de París de 1925 supuso una manifestación concluyente de las ideas desarrolladas por Le Corbusier sobre el diseño de objetos. Su postura contradecía firmemente las bases del estilo Art-Déco ${ }^{3}$, mayoritario en la exposición de París, que se convertiría en uno de los objetivos principales de crítica del arquitecto. En su libro L'art décoratif d'aujourd'hui explicaba cómo el propio título, que hacía referencia a la muestra del 25 , presentaba una paradoja: "el arte decorativo moderno no tiene decoración ",

La paradoja radicaba no en el hecho, sino en las palabras, en la contradicción de hacer arte de herramientas: “¿Por qué deberíamos denominar todas estas cosas que nos ocupan en la actualidad, arte decorativo? Ahí reside la paradoja: ¿Por qué denominar arte decorativo a las sillas, las botellas, las cestas, los zapatos, todos los objetos útiles, los utensilios? Es una paradoja querer hacer arte con los utensilios „5. Por esta razón, la definición del término arte también se convertía en cardinal para comprender la base de sus teorías. Sólo si el arte era considerado la aplicación de conocimientos para la realización de una idea ${ }^{6}$, podía aplicarse a los objetos de uso. Por el contrario, el arte entendido como decoración o como "manifestación de la actividad humana mediante la cual se expresa una visión personal y desinteresada que interpreta lo real o imaginado con recursos plásticos, lingüísticos o sonoros”, no tenía sentido en la creación de bienes utilitarios.

"Y todos los sarcasmos emitidos acerca del objeto único, del mueble de arte, suenan a falso y prueban una incomprensión enfadosa de las necesidades de la hora presente: una silla no es una obra de arte; una silla no tiene alma; es una cosa para sentarse",7.

\subsection{Ausencia de ornamento}

Le Corbusier se hacía eco de las reflexiones expuestas por Adolf Loos años antes, afirmando que "cuanto más

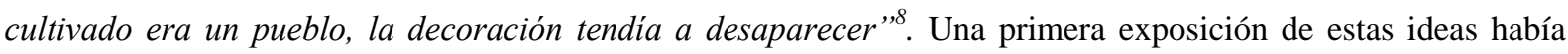

\footnotetext{
${ }^{3}$ Frampton, Kenneth: Le Corbusier. Madrid: Akal, 2002, p.22.

4 “L'art dècoratif moderne n'a pas de décor". Le Corbusier: L'art décoratif d'aujourd'hui. Paris: G. Crès \& Cie., 1925, p.84.

${ }^{5}$ Idem. "Pourquoi appeler ces choises qui nous occupent presentemente: art décoratif? Voilà le paradoxe; pourquoi appeler art décoratif des chaises, des bouteilles, des paniers, des chaussures, Tous objets utiles, des outils?" (Traducción al español extraída de Le Corbusier: El arte decorativo de hoy. Carlos Naya Villaverde e Inmaculada Jiménez Caballero (ed.) Maurici Pla Serra (trad.). Pamplona: EUNSA, 2013).

${ }^{6}$ Le Corbusier: L'art décoratif d'aujourd’hui, op.cit., p.84.

${ }^{7}$ Le Corbusier: Vers une architecture. Paris: G. Crès \& Cie., 1923, p.112. (Traducción al español extraída de Le Corbusier: Hacia una arquitectura. Barcelona: Ediciones Apóstrofe, 1998).

8 "Plus un peuple se cultive, plus le décor disparaît". Le Corbusier: L'art décoratif d'aujourd hui, op.cit., p.85.
} 
tenido lugar en Vers une architecture en 1923, en donde el maestro suizo, por un lado, afirmaba que los objetos de uso tenían que mostrarse desprovistos de toda ornamentación; y, por otro, mantenía que toda expresión humana necesitaba "una cierta dosis de interés y sobre todo en el dominio estético", y los objetos podían ser considerados como expresión del hombre, puesto que él los había creado.

Aquel interés se manifestaba de dos maneras distintas dependiendo del nivel cultural del individuo. Le Corbusier distinguía entre aquellos que calificaba como pueblos sencillos y la civilización culta. En los primeros se producía de manera sensorial y primaria mediante la 'decoración'; sin embargo, para los segundos, surgía motivado por el orden intelectual, a través de la 'proporción' ${ }^{10}$. De este modo, la proporción era el único principio de captación del interés del hombre culto y la única manera de crear armonía; una armonía que se alcanzaba mediante la aplicación de la 'norma', es decir, "una necesidad de orden llevada al trabajo humano",l, que se establecía sobre bases funcionales, económicas y estéticas.

\subsection{Objetos-tipo}

La teoría formal de los bienes de uso de Le Corbusier estaba fundada, en parte, en la creencia de una correspondencia con el principio biológico de la selección natural. El arquitecto aplicó el concepto 'darwiniano' ${ }^{12}$ de la evolución al ámbito de las formas industriales, afectando así tanto al objeto como al usuario. Por un lado, se había producido un proceso de depuración de los objetos de uso en el cual se habían visto despojados de toda decoración alcanzando una mayor pureza y simplicidad formal. Por otro lado, el ser humano había experimentado un progreso debido a los objetos útiles, sus nuevas extensiones físicas, llamadas por Le Corbusier objets-membres humains.

Aunque el desarrollo de esta idea se llevó a cabo de un modo más amplio en L'art décoratif d'aujourd’hui, y más concretamente en el capítulo "Besoins-types, meubles-types", Le Corbusier ya había expuesto sus primeras reflexiones acerca de este tema en Vers une architecture ${ }^{13}$. Los objets-membres humains eran el resultado material de una búsqueda del hombre por satisfacer sus necesidades; unas necesidades comunes a las de todos los seres humanos: "Todos los hombres tienen el mismo organismo, las mismas funciones. Todos los hombres tienen las mismas necesidades" $"$. Sin embargo, el ser humano debía complementar sus capacidades naturales para adaptarse a su tiempo a través de la creación de las herramientas adecuadas y perfectas. Estos útiles eran objetos-tipo que respondían a unas necesidades-tipo de un hombre-tipo ${ }^{15}$.

\footnotetext{
9 “Toute manifestation humaine nécessite un certain quantum d'intérêt et surtout dans le domaine esthétique”. Le Corbusier: Vers une architecture, op.cit., p.112.

${ }^{10}$ Le Corbusier: Vers une architecture, op.cit., p.113.

${ }^{11}$ La palabra que utiliza Le Corbusier en Vers une architecture es standart. En la traducción española se sustituye por norma. Le Corbusier: Vers une architecture, op.cit., p.107.

${ }^{12}$ Le Corbusier explica el proceso de perfeccionamiento de los objetos a través de una terminología evolutiva que remite a Darwin. Estas reflexiones aparecen en varios párrafos del texto de L'art décoratif d'aujourd'hui; sin embargo, en la página 54 este procedimiento se aprecia especialmente. Frampton también hace referencia en su texto Le Corbusier a este modo de narrar el desarrollo de los objetos. Frampton, Kenneth: Le Corbusier, op.cit., p.21.

${ }^{13}$ Le Corbusier: Vers une architecture, op.cit., p.108.

${ }^{14}$ Idem. ("Tous les hommes ont même organisme, mêmes fonctions. Tous les hommes ont mêmes besoins"). Esta idea es expuesta en los tres textos, manteniéndose constante toda su vida. Finalmente, siguiendo estas ideas elaboraría en los 50 Le Modulor, unidad de medida de su obra.

${ }^{15}$ Le Corbusier: L'art décoratif d'aujourd'hui, op.cit., p.76.
} 


\subsection{Standard}

Para ello, lo racional era crear objetos standard de dimensiones standard y que además se adecuasen a las medidas del cuerpo del hombre. El resultado de estas piezas debía caracterizarse por la precisión, lo cual obligaba a ejecutarlos con una máquina. Para ello se comenzaron a utilizar los nuevos materiales en campos que antes no se habían empleado, introduciéndose inevitablemente en las industrias de artes decorativas, lo que transformó desde el modo de producción hasta la forma de los objetos. Este progreso, caracterizado por la aportación de nuevas técnicas como el tubo de acero o la soldadura autógena, proporcionó unos medios de realización infinitamente más perfectos y más eficaces que los desarrollados anteriormente.

La clave para la óptima creación de estos objetos se encontraba en su correcto dimensionamiento. En la era maquinista esto ya no era considerado un problema, pues la industria de la madera y del metal podían construir objetos precisos de funcionamiento admirable y de una dimensión no aproximada, sino cierta. Le Corbusier proponía incorporar en las viviendas objetos standard que cumpliesen una función y cuya forma estética llenase el corazón y la sensibilidad de un hombre moderno. Tan sólo eran necesarios tres tipos de objetos para cubrir las necesidades del ser humano en materia de mobiliario doméstico: la mesa, el asiento y el casillero ${ }^{16}$.

\subsection{Mesa}

Le Corbusier proponía distribuir varias mesas standard en cada apartamento, con el propósito de satisfacer necesidades diferentes. Recomendaba la disposición de dos o tres piezas yuxtapuestas de tamaños diferentes de tal modo que el espacio se convirtiese en espacio polivalente, un espacio flexible que se adecuase a las distintas funciones del hombre: la mesa de mayor tamaño podría servir para comer, otra de ellas para trabajar y quizás las más pequeñas podían desempeñar una función de apoyo. Asimismo las mesas podían ser utilizadas como complementos las unas de las otras y no sólo como elementos independientes (1).

El proceso de fabricación de las mesas debía ser industrial. Además Le Corbusier apostaba por el empleo de los nuevos materiales; concretamente sugería que las mesas fueran construidas con tubos de acero. La unión de estas piezas debía producirse mediante una soldadura autógena ${ }^{17}$; de este modo, permitía fijar la bandeja por un sistema de ajuste automático, facilitando el transporte y la ubicación de las piezas para cualquier ocasión ${ }^{18}$. Con este sistema de mesas yuxtapuestas, Le Corbusier conseguía flexibilidad del espacio doméstico y comodidad para sus habitantes.

\footnotetext{
${ }^{16}$ Le Corbusier: Precisiones respecto a un estado actual de la arquitectura y del urbanismo. Johanna Givanel (trad.). Poseidón: Barcelona, 1978, p.131. ("Afirmoles a ustedes que exceptuando los asientos y las mesas, los muebles no son, a decir verdad, sino casilleros").

${ }^{17}$ Según la Real Academia de la Lengua Española, la soldadura autógena es una soldadura de metales, que se hace, sin intermedio de materia extraña, fundiendo con el soplete de oxígeno y acetileno las partes por donde ha de hacerse la unión.

${ }^{18}$ Le Corbusier: Precisiones respecto a un estado actual de la arquitectura y del urbanismo, op.cit., p.139.
} 


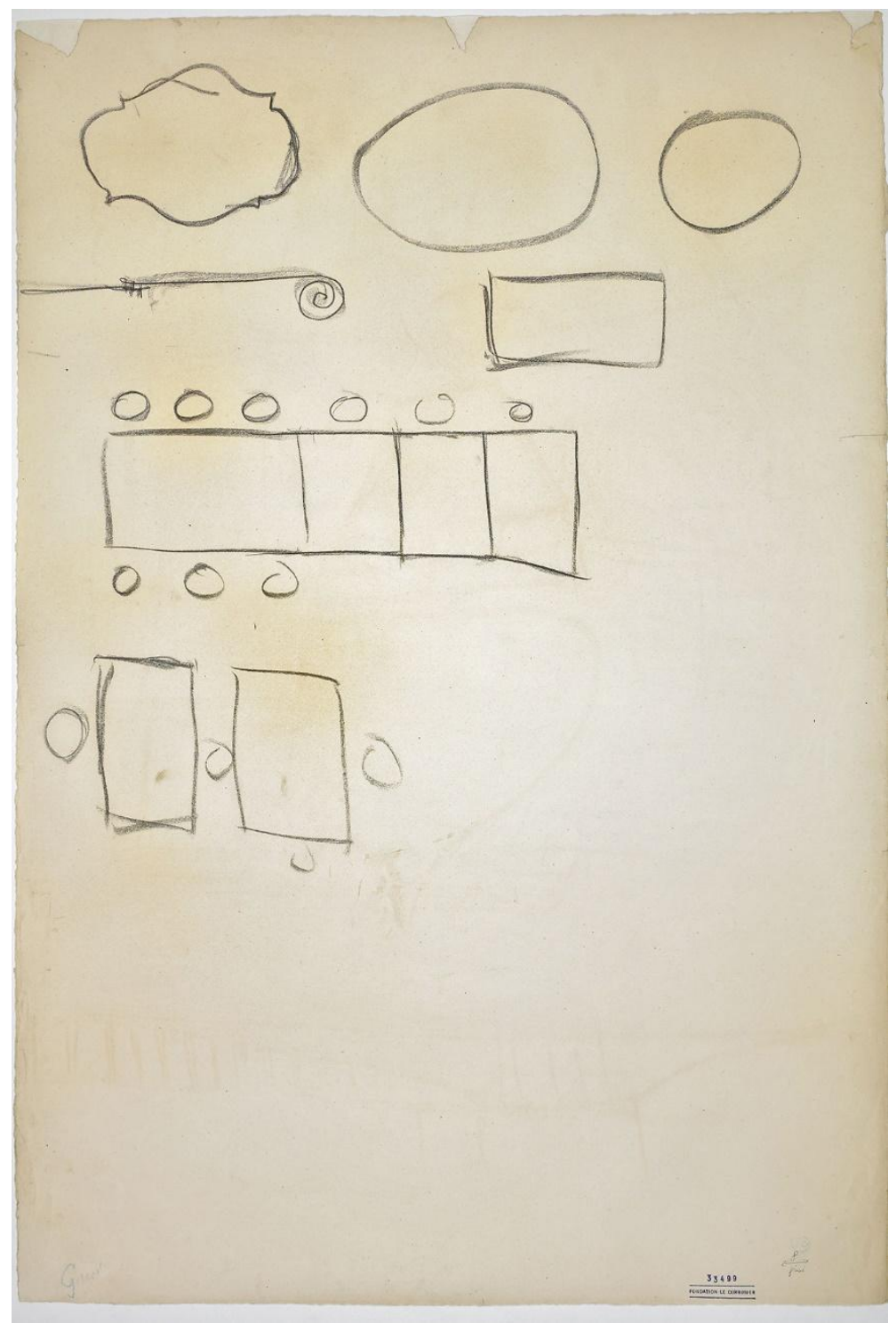

1. Dibujo de unas mesas en planta realizado por Le Corbusier. Plan FLC 33499

\subsection{Asiento}

Dependiendo del momento del día, de las preocupaciones de las personas y la actitud adoptada en un salón existían varias maneras de sentarse. Respondiendo a esta diversidad de posturas, Le Corbusier consideraba que debían utilizarse en cada situación las piezas de mobiliario adecuadas. Para trabajar se requería la silla, puesto que se trataba de un instrumento que por su morfología permitía al usuario mantenerse "en activo". Para demostrar una tesis, la pieza idónea era el taburete alto porque, además de mantener al orador activo, lo situaba en posición elevada frente a su público. Para charlar, el sillón era el asiento más adecuado pues dotaba al usuario de un porte decente y cortes. Para descansar, la opción más acertada era el taburete turco ${ }^{19}$ donde se conseguía un fabuloso estado de tranquilidad y relajación (2).

\footnotetext{
${ }^{19}$ Idem. Le Corbusier explicaba, asimismo las características del taburete turco de los "cavedjis" de Estambul, cuyas medidas eran 35 centímetros de alto y de 30 centímetros de diámetro.
} 
El mobiliario no sólo dependía de estos factores, vinculados en gran medida con las actividades del hombre, sino que también debía responder a cuestiones prácticas y funcionales, como por ejemplo, el número de asistentes o la menor ocupación del espacio en su almacenamiento. Para solventar ambas situaciones, la industria había creado sillas y taburetes apilables que resultaban de gran utilidad en momentos de gran concurrencia. Estas piezas de mobiliario podían encajarse unas en otras, de manera que su almacenamiento era rápido, situándolas en altura y ocupando menos espacio.

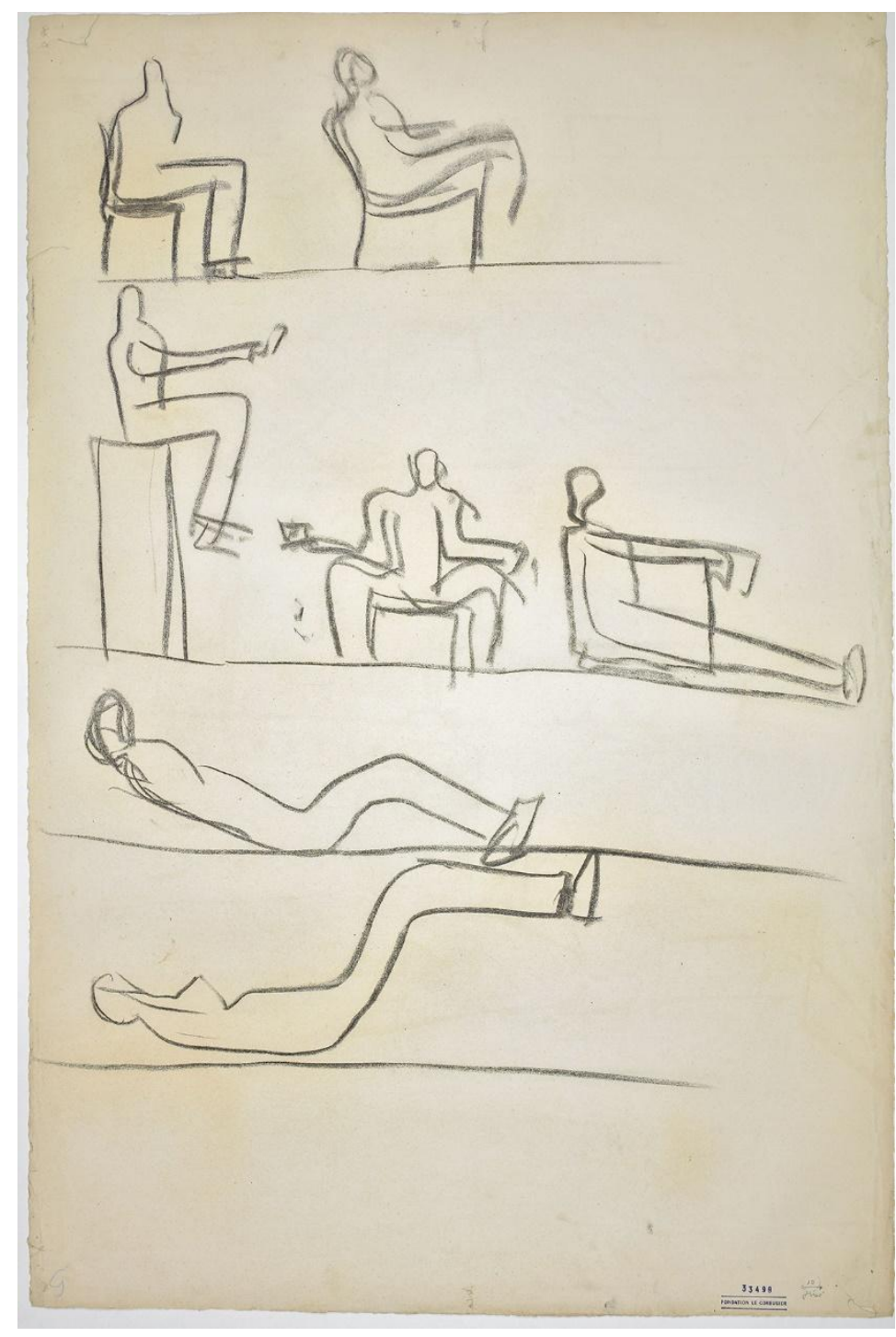

2. Dibujo realizado por Le Corbusier para mostrar las diferentes formas de sentarse. Plan FLC 33499

\subsection{Casillero}

Para Le Corbusier, el inventario de los objetos de uso diario del hombre se resumía en dos imágenes. En una de ellas mostraba los instrumentos para comer situados en un casillero: un estante con la cristalería, otro con la vajilla, otro con botellas y unos cajones con la cubertería. En la segunda, presentaba los elementos textiles necesarios, desde la ropa de cama, ropa interior, lencería, medias... hasta el traje y zapatos. Todos ellos habían sido diseñados según los miembros del cuerpo humano, por lo que almacenar eficazmente era necesario un mueble que también lo estuviera. Le Corbusier proponía para ello la utilización del casillero, y a través de otro de sus dibujos (3), las dimensiones exactas que debía tener: 

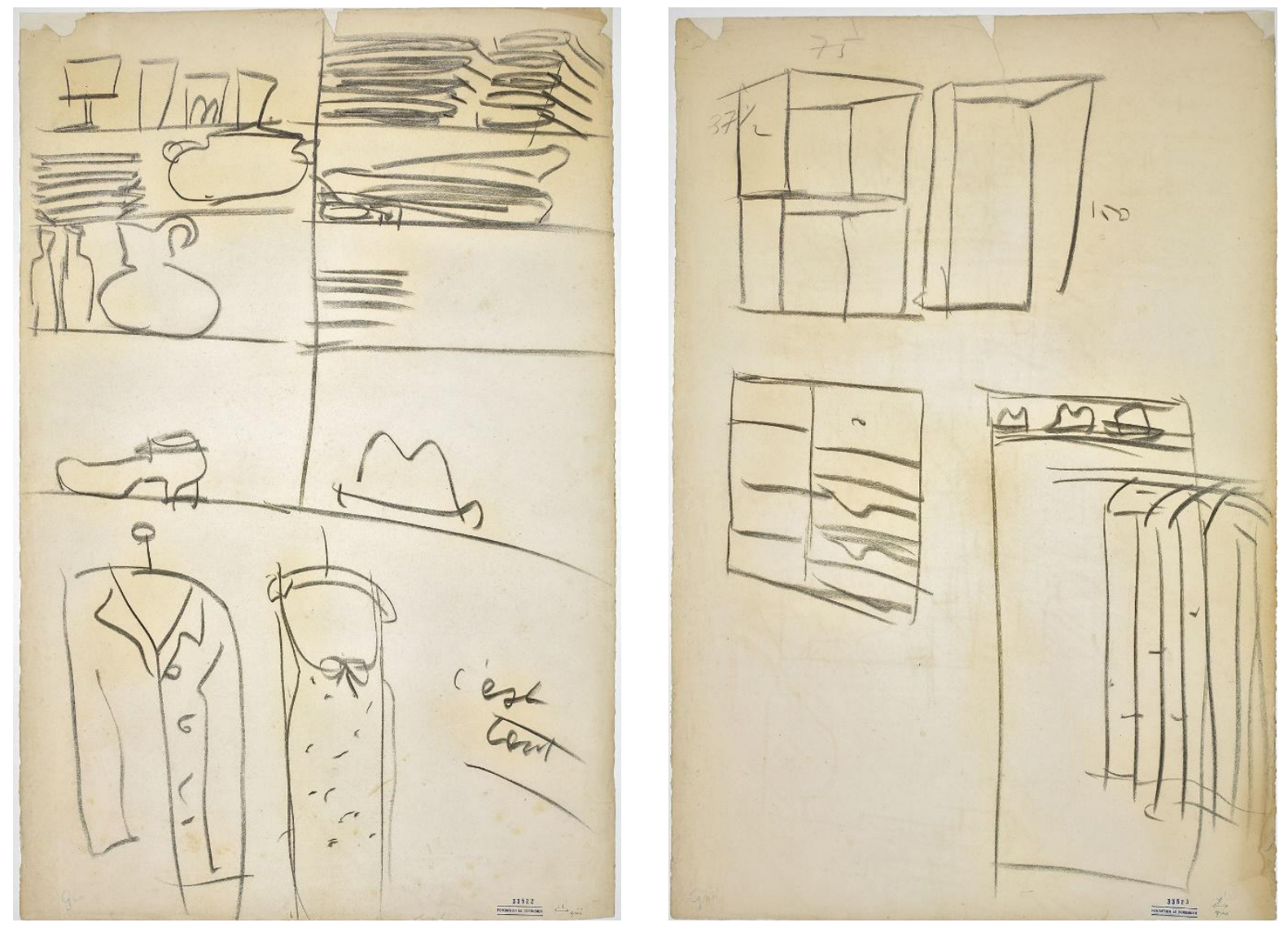

3. Dibujos realizados por Le Corbusier para ilustrar los objetos que hay que almacenar en una vivienda y la adecuación del casillero para este uso. Plan FLC 33522 (izda.), plan FLC 33523 (dcha.)

"Dibujo este casillero. Tiene 75 centímetros de lado y 37,50 a 50 centímetros de profundidad o $150 \times 75$ de frente y 37,50 a 75 de profundidad. La movilidad de la cota de profundidad resulta de los diversos métodos de arreglo interior de este casillero ${ }^{, 20}$.

Le Corbusier propuso una solución que afectaba a todos los órdenes: constructivo, económico e industrial: "Seria oportuno crear, industrialmente, unos casilleros, unos 'continentes', en gran serie, vendibles al particular que arregla su casa y al arquitecto que proyecta los planos ${ }^{, 21}$. De este modo, el propietario y habitante de la vivienda podría disponer los casilleros contra las paredes de sus habitaciones o construir con ellos unos tabiques nuevos a plena o a media altura, y por otro lado, el arquitecto podría incorporar en obra los

${ }^{20} \mathrm{Ibid}, \mathrm{p} .133$. Este conjunto de números no eran aleatorios, sino que respondían a unas necesidades estudiadas por el propio Le Corbusier, fruto de su reconocida experiencia en espacios expositivos e interiores. En el año 1913, realizó un proyecto para una exposición ambulante de arte decorativo, en el que debía dibujar un material desmontable que consistía en una batería de cocina que iba desde el office al salón y al "boudoir". En esta ocasión Le Corbusier halló un módulo de 75 centímetros y de 150 centímetros. Más tarde, en 1924, durante la preparación del Pabellón de L'Esprit Nouveau volvió a llegar a aquellas dimensiones tras un severo análisis, confirmándolas un año después, tras la inauguración del Pabellón. Finalmente, en 1928 Charlotte Perriand, asociada a Le Corbusier para la instalación de los interiores de las casas, llegó a la misma conclusión al realizar el proyecto para el Salón de Otoño de París en 1929. La instalación de dicha exposición pretendía demostrar de modo concluyente, el principio del "equipamiento de una habitación moderna", amueblada con sillas, mesas y casilleros standard.

${ }^{21}$ Ibid, p.135. 
casilleros introduciéndolos en el interior de las paredes. Así, casi todas las funciones del mobiliario del hogar estarían solucionadas. El único aspecto que quedaba por equipar era el interior de los casilleros, que se realizaría por medio de estantes y cajones ${ }^{22}$.

\subsection{Espacio}

Le Corbusier manifestó en distintas ocasiones que el interés en el mobiliario no se limitaba únicamente al propio objeto, sino que trascendía, influyendo de un modo directo en la arquitectura, en el "hombre y su ambiente"23. Con la llegada de nueva arquitectura, las viviendas se vaciaron de mobiliario obsoleto y se llenaron de luz, espacio y nuevos muebles adecuados a su tiempo. Para ilustrar de qué manera el mobiliario moderno era capaz de liberar espacio ${ }^{24}$, Le Corbusier analizó y comparó la planta y la sección de un dormitorio tradicional con las de uno moderno (4). A diferencia del primero, el segundo ofrecía un mayor aprovechamiento del espacio, mejora de las circulaciones, y un perfeccionamiento de las formas. El dormitorio tradicional, sin embargo, entorpecía la estancia por el gran tamaño y excesivo peso de sus muebles ${ }^{25}$.
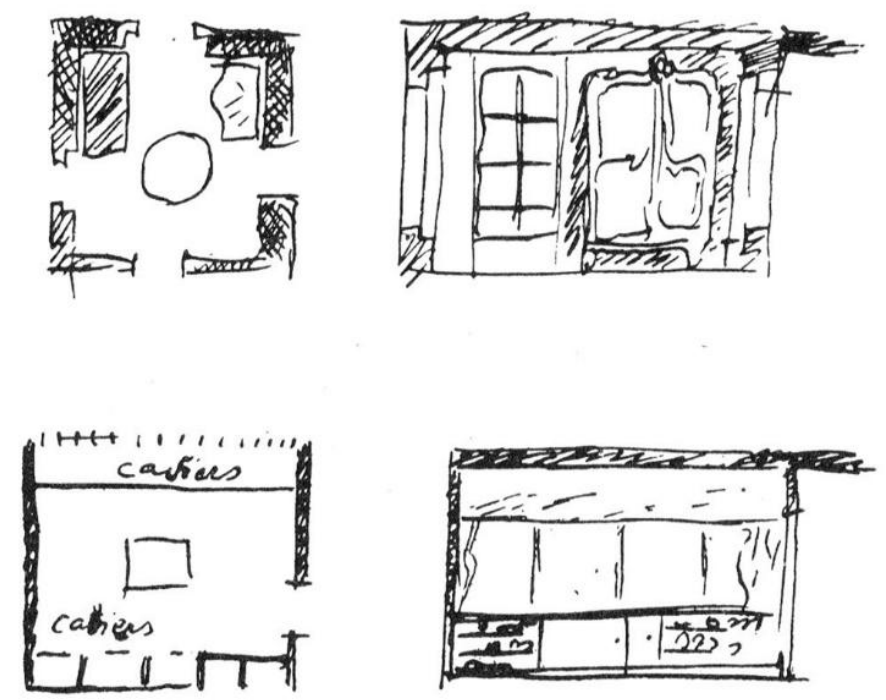

4. Dibujo realizado por Le Corbusier que compara el espacio de una habitación tradicional y otra moderna. Fuente: Le Corbusier: Precisiones respecto a un estado actual de la arquitectura y del urbanismo, p.132.

Le Corbusier estaba convencido de que no se enfocaría con eficacia la renovación del plano de la casa moderna sino después de haber puesto al desnudo la cuestión del mobiliario. "Aquí está el nudo gordiano. Hay que cortarlo, de lo contrario toda persecución de vida moderna es vana" 26 . Arquitectura y mobiliario estaban claramente vinculados hasta tal punto que dependían el uno del otro, cuestión que sería objeto de la experimentación del arquitecto a lo largo de toda su vida.

\footnotetext{
${ }^{22}$ Idem.

${ }^{23}$ Ibid, p. 10 .

${ }^{24}$ Las ilustraciones que aparecen en la publicación de Precisiones, según afirma su autor, son las mismas que dos años antes había empleado para explicar las características del mobiliario moderno en su conferencia "La aventura del mobiliario" celebrada en Argentina.

${ }^{25}$ Le Corbusier: Precisiones respecto a un estado actual de la arquitectura y del urbanismo, op.cit., p.135.

${ }^{26}$ Ibid, p. 127.
} 


\section{Hombre, objeto y ambiente}

Los proyectos desarrollados durante la segunda mitad de la década de 1920 por Le Corbusier, en colaboración con su primo Pierre Jeanneret, son manifiestos construidos a escala 1/1: la experimentación y corroboración de las ideas presentadas en sus escritos. Por esa razón, los cambios que experimentó su posición acerca de la relación establecida entre mueble y arquitectura se pueden apreciar tanto en su teoría como en su obra. Aunque la base de sus tesis, anteriormente expuesta, no sufre grandes modificaciones, se produce una importante transformación entre 1925 y 1928 que se tradujo en un mayor intervencionismo del arquitecto en el diseño de piezas standard.

La actitud adoptada en la Exposición de Artes Decorativas de París de 1925, ratificada tanto en el Pabellón de L'Esprit Nouveau como en su libro L'art décoratif d'aujourd 'hui, muestra su rechazo a la obra de arte total en la que el arquitecto lo diseña todo. Sin embargo, este posicionamiento se va flexibilizando a partir de la incorporación de Charlotte Perriand en 1927 al estudio de Le Corbusier y Pierre Jeanneret ${ }^{27}$. El Salón de Otoño de 1929 y su conferencia "La aventura del mobiliario" confirman esta evolución hacia una mayor participación del arquitecto en el diseño de objetos domésticos standard.

El punto de partida de este desarrollo es el Pabellón de 1925 (5), no sólo por la manera de amueblar la instalación - muy similar a la ya realizada en la casa La Roche/Jeanneret- sino también, y muy especialmente, por su carácter de manifiesto que complementaba a su libro L'art décoratif d'aujour 'hui. En este proyecto, Le Corbusier, de nuevo influenciado por Adolf Loos - algo que el propio arquitecto suizo reconocía sin ambages, amuebló el espacio fundamentalmente con piezas ya existentes en el mercado. Su elección estaba claramente marcada por el carácter utilitario y casi anónimo de los objetos, que provenían tanto del mundo artesanal como industrial.

\footnotetext{
${ }^{27}$ A raíz de la exposición de su Bar bajo el tejado (Bar sous le toit) en el salón de la Sociedad de artistas decoradores, Charlotte Perriand logró llamar la atención de Le Corbusier quien le permitió incorporarse a su estudio. Perriand influida por la lectura de Vers une architecture y L'art décoratif d'aujourd hui diría de estos textos que abrieron el muro que tenía ante sus ojos; además de servir de inspiración para la creación de sus piezas. McLeod, Mary: Charlotte Perriand. An Art of Living. New York: H.N. Abrams in association with the Architectural League of New York, 2003, p.36.
} 


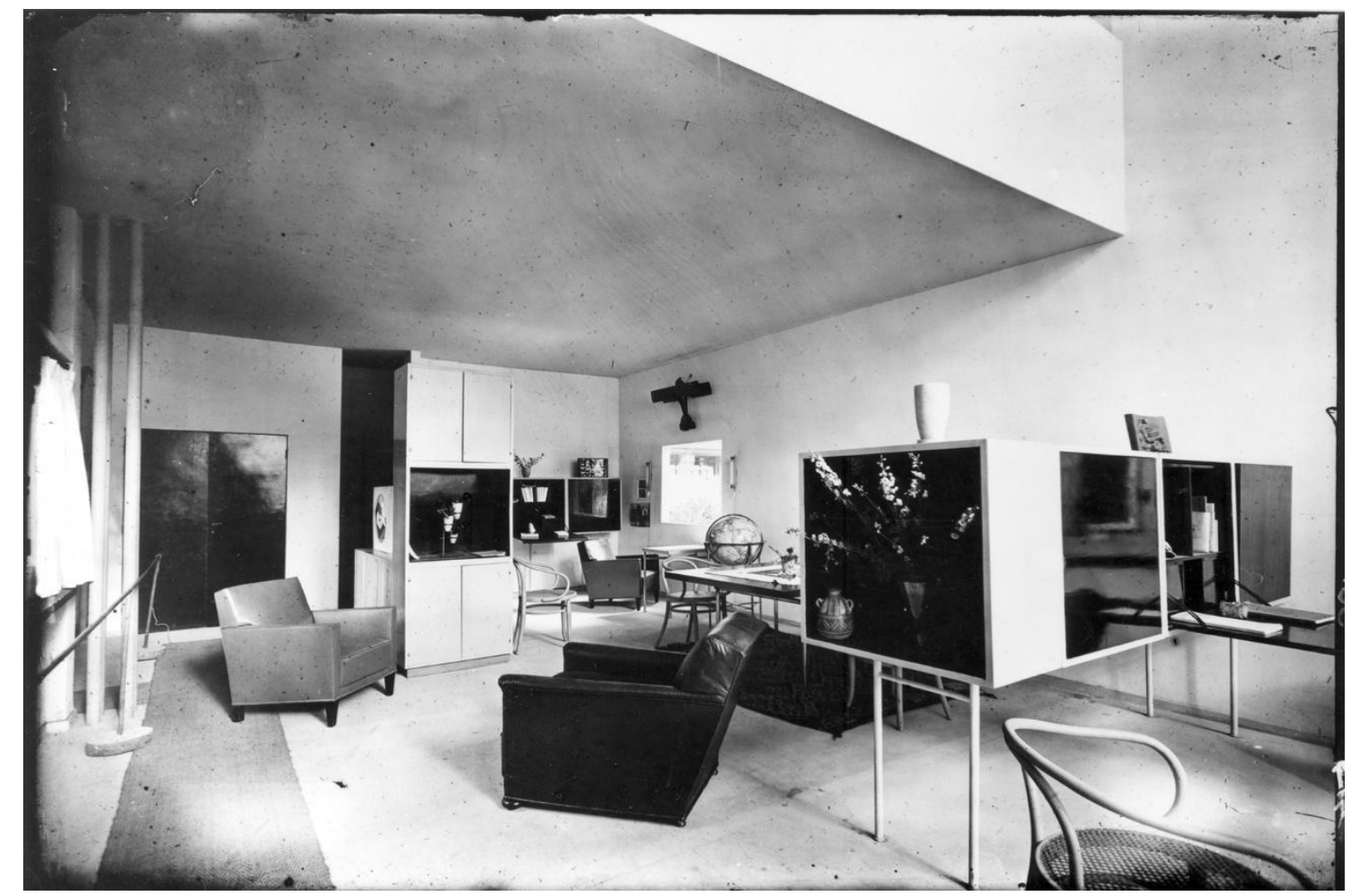

5. Fotografía del interior del Pabellón de L’Esprit Nouveau, París, 1925. Fuente: Fondation Le Corbusier. (C) FLC-ADAGP

Según recoge Arthur Ruegg en su libro Le Corbusier: Meubles et intérieurs 1905-1965, se expusieron los siguientes objetos estándar: silla de oficina de Jacob \& Josef Kohn / Thonet Fréres (Viena-París) y Robert Mey (París), muebles de metal para jardín, tres sillas de cuero del club silla Abel Motte (París, ejecuciones según las indicaciones de Le Corbusier y Pierre Jeanneret), un baúl de viaje de la firma de Innovación (París) ${ }^{28}$. Entre estas piezas destaca el modelo 209 de Thonet que Le Corbusier utilizaría para amueblar, entre otras, la casa La Roche y las Weissenhofsiedlungen de Stuttgart, y que serviría de referencia para diseños propios como la silla pivotante.

Pero además fueron exhibidas en la muestra piezas diseñadas por Le Corbusier y Pierre Jeanneret: mesas $^{29}$, camas y unos casilleros estándar, presentados por primera vez en la exposición (6). Estos últimos no sólo constituyeron un nuevo diseño de un mueble de almacenamiento, sino que presentaban una nueva manera de equipar la vivienda moderna, tal y como el arquitecto lo expondría en sus escritos. Por un lado, el casillero había sido ideado como un elemento standard que estaba equipado de manera diferente según las necesidades del usuario (con estantes, cajones, espacio para ropa...). Por otro, el mueble estaba estratégicamente situado para crear circulaciones y definir espacios, tal como lo expuso en su libro Précisions sur un état présent de l'architecture et de l'urbanisme.

\footnotetext{
${ }^{28}$ Rüegg, Arthur: Le Corbusier: Meubles et Intérieurs 1905-1965, Zurich: Scheidegger \& Spiess AG, 2012, p.252-254.

${ }^{29}$ Ibid, p.250.
} 


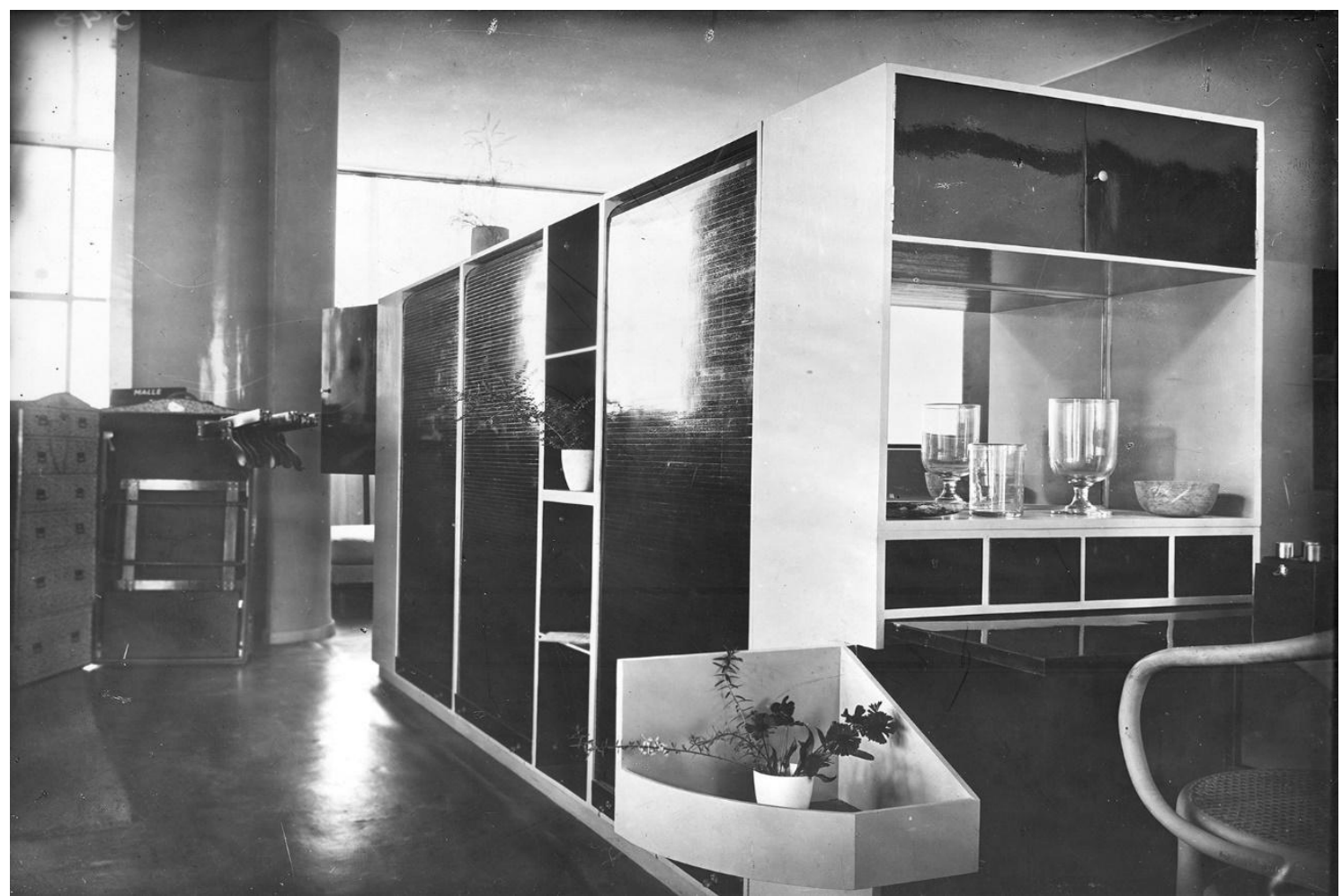

6. Fotografía de los casilleros instalados en el Pabellón de L’Esprit Nouveau, París, 1925. Fuente: Fondation Le Corbusier. (C) FLC-ADAGP

El pabellón era un espacio visualmente homogéneo "producto de una sola mentalidad creadora"30. Tal y como explicaba Frampton, la instalación mostraba un amueblamiento de acuerdo con el canon purista basado principalmente en objetos-tipo combinados con objetos-mesa; alfombras orientales y alfarería suramericana. El perfeccionamiento propio del mueble producido en serie, además de satisfacer funciones formales debido a su correcta ejecución, proporcionó una estética interior del pabellón que impactó tanto a organizadores como visitantes de la exposición. Se trataba, además de una protesta contra el Art Déco y sus seguidores, de una exposición pública de las propuestas espaciales de Le Corbusier para la modernidad ${ }^{31}$, que consistía principalmente en una actitud selectiva, basada en la elección de unos elementos standard disponibles en el mercado, y creando otros objetos-tipo con vocación de seriación.

A partir de entonces, la relación que Le Corbusier establecía entre mueble y arquitectura fue modificándose paulatinamente y experimentando un verdadero cambio que coincide con la entrada de Perriand en el estudio en 1927. Aunque a su llegada, el maestro suizo ya tenía un claro concepto de mobiliario moderno, su posición comenzó a tornarse más flexible hacia una postura normativa en la que el arquitecto también desarrollaba su propio mobiliario a través del lenguaje moderno. Una de las razones que motivaron este cambio, según apunta McLeod $^{32}$, fue la fascinación de Le Corbusier por los muebles de tubo de acero diseñados por Breuer y Mies van der Rohe. Al igual que ellos, y debido a su insatisfacción con los productos fabricados industrialmente, Le

\footnotetext{
${ }^{30}$ Banham, Reyner: Theory and Design in the first Machine Age. Londres: The Architectural Press, 1960, p.245.

${ }^{31}$ Frampton, Kenneth: Historia crítica de la arquitectura moderna. Barcelona: Gustavo Gili, 2002, p.157.

${ }^{32}$ McLeod, Mary: Charlotte Perriand. An Art of Living. New York: H.N. Abrams in association with the Architectural League of New York, 2003, pp.37-38.
} 
Corbusier contrató a Perriand para encargarse del mobiliario y poder diseñar prototipos de muebles en su propio taller.

Surgieron de este momento las piezas más famosas del estudio de Le Corbusier. Se trataba de la serie de muebles de tubo de acero y piel, creados entre 1927 y 1929, considerados hoy verdaderos clásicos del diseño del siglo XX. Entre ellos destacan el sillón de respaldo basculante, el gran confort, la Chaise longue — considerada por Le Corbusier "la verdadera máquina de reposo"33 _, la silla giratoria y la mesa-tubo de avión con tablero de vidrio. Resulta especialmente interesante destacar, tal y como lo explica Frampton, por una parte, que cada una de las piezas corresponde a una postura concreta del cuerpo humano y, por otra, que algunas derivaban de una tipología particular de mueble ya existente. La silla gran confort estaba inspirada en el sillón club inglés y exigía una postura frontal asociada a la silueta masculina. El sillón de respaldo basculante derivaba del tradicional sillón plegable de campaña británico. Las sillas giratorias estaban inspiradas en la clásica silla de mecanógrafa. La chaise longue, asociada a la forma femenina, era una pieza diseñada para el descanso ${ }^{34}$.

Todas estas piezas respondían a las características del mobiliario moderno expuestas por Le Corbusier en sus escritos previos - ausencia de ornamento, objetos-tipo para funciones-tipo, dimensiones standard, adecuación al espacio, entre otras - , por lo que eran ejemplos materiales de su teoría; algo que se reafirmaría cuando en 1930 la casa Thonet produjo varios modelos en pequeñas series ${ }^{35}$ que pasarían a formar parte de sus catálogos (7). La firma de muebles ofrecía estos modelos entre otros realizados por conocidos diseñadores del momento. Las obras de Marcel Breuer, Mart Stam, Ludwig Mies van der Rohe o André Lurçat, fueron recogidas en el catálogo, re-editado por Vitra Design Museum-Vitra Design Publications en 1989, que presentaba la primera colección completa de modelos de acero tubular alemanes y franceses comercializados en 1930-1931, entre los que también se encontraban las piezas de Le Corbusier, Jeanneret y Perriand ${ }^{36}$.

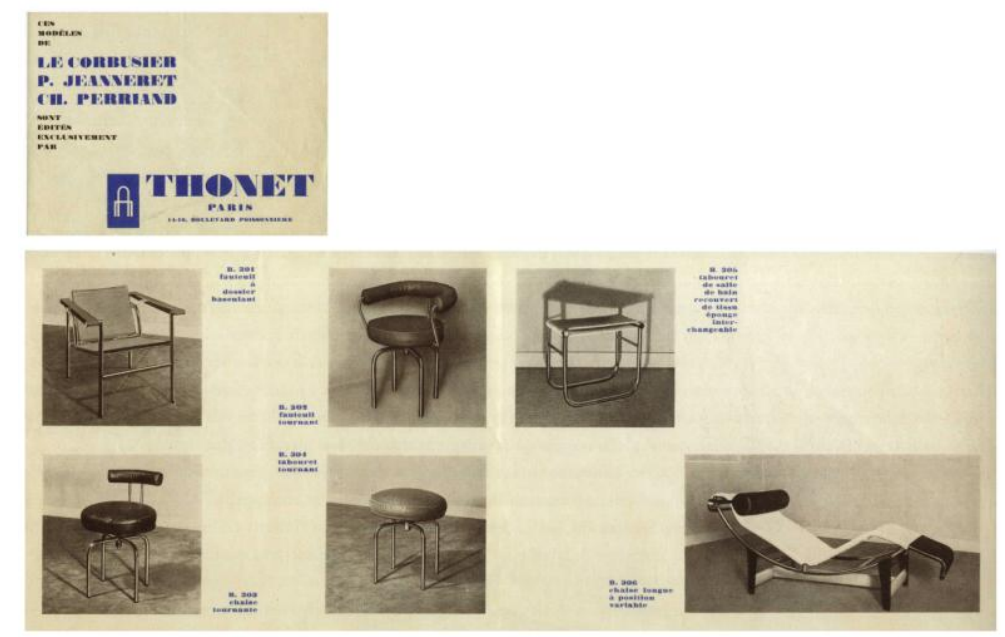

7. Folleto desplegable de la firma Thonet en París con los modelos de Le Corbusier, Jeanneret y Perriand, 1931. Fuente: Rüegg, Arthur: Le Corbusier: Meubles et Intérieurs 1905-1965, p.122 (Colección privada)

\footnotetext{
${ }^{33}$ Le Corbusier: Precisiones respecto a un estado actual de la arquitectura y del urbanismo, op.cit., p.142.

${ }^{34}$ Frampton, Kenneth: Le Corbusier, op.cit., p.51.

${ }^{35}$ A partir de 1965 sería la firma Cassina la encargada de producirlos, bajo licencia de la Fondation Le Corbusier.

${ }^{36}$ Gunther, Sonja: Thonet tubular steel furniture card catalogue. Well-Am-Rhein: Vitra Design Museum, 1989.
} 
Tan sólo un año antes, aquellas piezas —entonces prototipos- habían sido expuestas en el Salón de Otoño junto con unos casilleros modulares, modificables e intercambiables, similares a los ya presentados en el Pabellón de L'Esprit Nouveau. Desde 1925 el arquitecto fue transformando los casilleros y ajustando su diseño a las necesidades de un usuario-tipo, tratando de producir modelos standard adecuados a la vivienda moderna. Estas unidades de almacenamiento fueron claves en el desarrollo de la obra de Le Corbusier, convirtiéndose en objeto de estudio del arquitecto y pieza indispensable en muchas de sus obras.

En enero de 1929 ya se había realizado una primera versión de los casilleros metálicos que iban a ser expuestos en el Salón de Artistas Decoradores de ese mismo año. Finalmente, aquella presentación pública no se llevó a cabo y aquel primer prototipo realizado por la casa Blanc de París no prosperó debido a cuestiones técnicas elementos de chapa inestables o desperdicio de material innecesario-, tal y como lo explica Rüegg ${ }^{37}$. La segunda versión fabricada por Thonet Frères se expuso en el Salón de Otoño de 1929 (8). Le Corbusier, Jeanneret y Perriand proyectaron un modelo íntegramente equipado, en el que todos los casilleros constaban de estantes desmontables y ligeros que permitían modular y distribuir el espacio interior. Tras este diseño se realizaron proyectos de simplificación de los casilleros, algunos sin trascender más allá del papel y otros llegando a construirse como el casillero Rivier de 1930 o Lakarmé de 1931.

El objetivo de la propuesta realizada para el Salón de Otoño de 1929 era diseñar un apartamento transformable, con piezas móviles y ligeras que, por una parte, colaborasen en la distribución y modulación de la arquitectura y, por otra, permitieran percibir y disfrutar el espacio proyectado. El conjunto de estos objetos fue presentado al público como 'Equipamiento de la vivienda', como parte de una instalación que mostrase al público un nuevo modo de habitar "en el espacio" y no "entre muebles"38. El Salón de Otoño del 29 supuso la confirmación de sus ideas divulgadas en sus conferencias por Argentina y de sus escritos, al tiempo que sirvió como medio para publicitar el mobiliario producido en el atelier que utilizaría en muchas de sus obras posteriores, incluida su vivienda, el Inmueble Molitor.

\footnotetext{
${ }^{37}$ Rüegg, Arthur: Le Corbusier: Meubles et Intérieurs 1905-1965, op.cit. p.286.

${ }^{38}$ Mang, Karl: History of modern furniture. John William Gabriel (trad.). Londres: Academy Edition, 1979, p.119.
} 


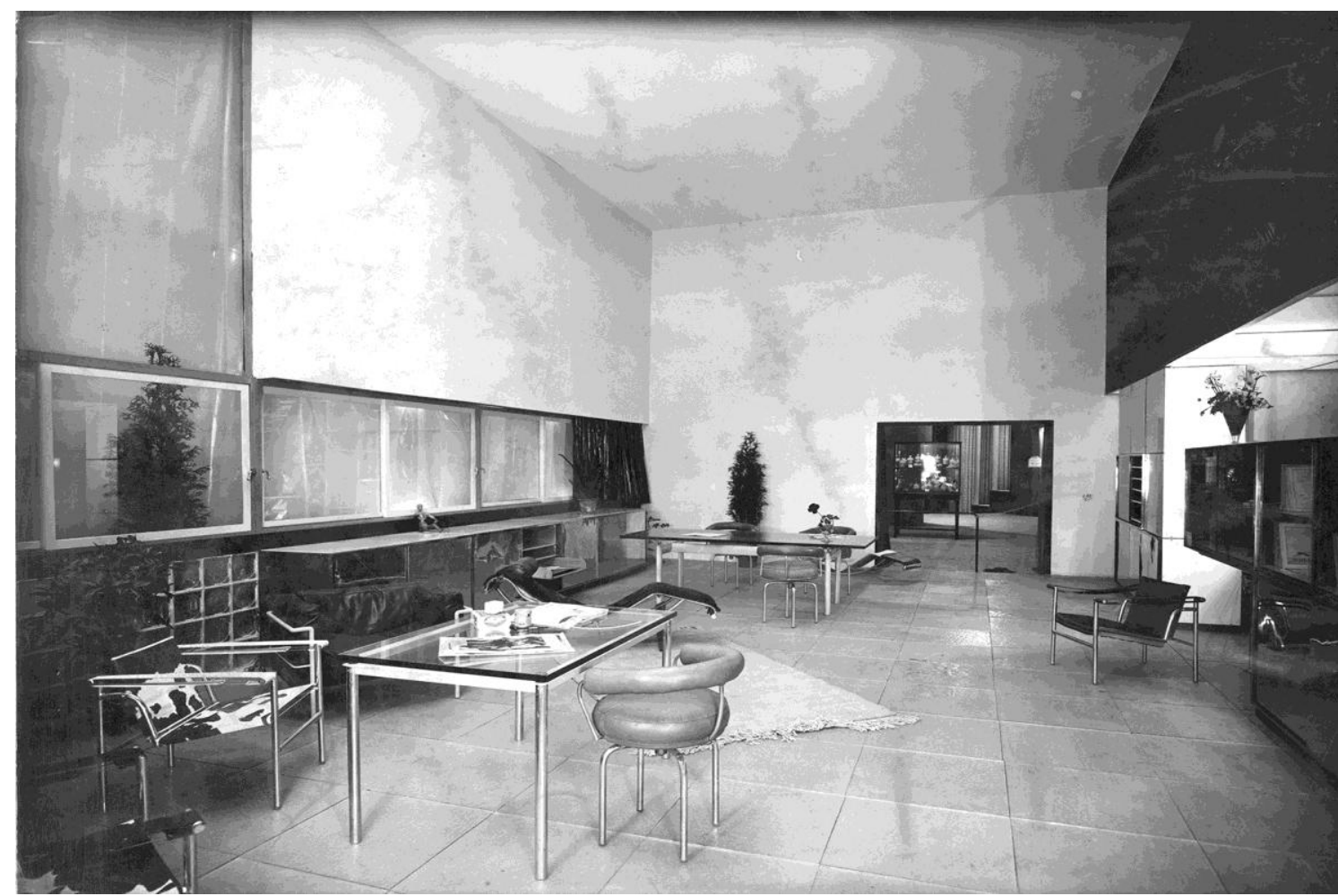

8. Fotografía de la instalación del Salón de Otoño de 1929 de Le Corbusier, Jenneret y Perriand. Fuente: Fondation Le Corbusier. (c) FLC-ADAGP

\section{Teoría y obra: argumentos sobre una caracterización 'corbuseriana' del mobiliario moderno}

Tras el análisis del legado de Le Corbusier en el campo del diseño, es posible apreciar una estrecha relación entre su obra escrita y construida. Las primeras intuiciones divulgadas en Vers une architecture y los posteriores postulados publicados en L'art décoratif d'aujour'hui son puestos en práctica en proyectos como la maison La Roche/Jeanneret o en el Pabellón de L'Esprit Nouveau en el que, además, son públicamente expuestos. Estos manifiestos teórico-prácticos ofrecen las claves para conocer la caracterización del mueble moderno según Le Corbusier; un verdadero cuerpo teórico, coherente, que se materializa en objetos concretos, sin ornamento, ligeros y standard -objetos-tipo que cumplen unas funciones-tipo para unas necesidades-tipo de un hombretipo $^{39}$ - y que en el Pabellón se evidencia con una actitud fundamentalmente selectiva del autor.

De aquellas ideas que establecen la base de su teoría, se desarrollan otras que Le Corbusier expone en conferencias como las de Madrid y Argentina, y en su libro Précisions sur un état présent de l'architecture et de l'urbanisme. Se centran especialmente en la modulación y fabricación industrial de los objetos, así como en su utilización y su relación con el espacio. Algo que no sorprende al analizar sus obras entre 1927 y 1930, ya que se vuelven a ratificar las reflexiones enunciadas por Le Corbusier pero en este caso de forma más activa, gracias a la colaboración de Charlotte Perriand. Los prototipos diseñados para el interior de la villa Church, expuestos en el pabellón de Otoño del 29 y producido en serie por Thonet a partir de 1930, son la conclusión de sus ideas en tanto en cuanto se trata de unos objetos standard diseñados según unas medidas también standard, industrializados y por tanto, repetibles para un nuevo espacio: la vivienda moderna.

\footnotetext{
${ }^{39}$ Le Corbusier: L'art décoratif d'aujourd'hui, op.cit., p.76.
} 
En ese sentido, una de las principales aportaciones de Le Corbusier fue su innovadora concepción del espacio, en la que la arquitectura albergaba muebles, distribuidos como cuerpos independientes sobre el plano. Se trataba de elementos añadidos caracterizados por su cualidad móvil y materialidad ligera; por unas piezas que cumplían una función como objetos y una función espacial. No eran por tanto muebles sino objetos-tipo que al entrar en contacto con el espacio, lo dotaban de las funciones necesarias, es decir, lo equipaban. Lo que llevó a Le Corbusier a proponer una nueva definición 'corbuseriana' sobre el mobiliario moderno, ya que "la noción del mobiliario ha desaparecido. Se ha substituido por un vocablo nuevo: 'el equipo domestico', ${ }^{\text {, } 40}$.

\section{Agradecimientos}

Los autores agradecen a la Fondation Le Corbusier su colaboración y ayuda para la realización de la presente investigación.

\section{Procedencia de las imágenes}

1. Dibujo de unas mesas en planta realizado por Le Corbusier. Plan FLC 33499

2. Dibujo realizado por Le Corbusier para mostrar las diferentes formas de sentarse. Plan FLC 33499

3. Dibujos realizados por Le Corbusier para ilustrar los objetos que hay que almacenar en una vivienda y la adecuación del casillero para este uso. Plan FLC 33522 (izda.), plan FLC 33523 (dcha.)

4. Dibujo realizado por Le Corbusier que compara el espacio de una habitación tradicional y otra moderna. Fuente: Le Corbusier: Precisiones respecto a un estado actual de la arquitectura y del urbanismo. Johanna Givanel (trad.). Poseidón: Barcelona, 1978, p.132.

5. Fotografía del interior del Pabellón de L’Esprit Nouveau, París, 1925. Fuente: Fondation Le Corbusier. () FLC-ADAGP

6. Fotografía de los casilleros instalados en el Pabellón de L’Esprit Nouveau, París, 1925. Fuente: Fondation Le Corbusier. () FLC-ADAGP

7. Folleto desplegable de la firma Thonet en París con los modelos de Le Corbusier, Jeanneret y Perriand, 1931. Fuente: Rüegg, Arthur: Le Corbusier: Meubles et Intérieurs 1905-1965, p.122 (Colección privada)

8. Fotografía de la instalación del Salón de Otoño de 1929 de Le Corbusier, Jenneret y Perriand. Fuente: Fondation Le Corbusier. @ FLC-ADAGP

\section{Bibliografía/Referencias}

Banham, Reyner: Theory and Design in the first Machine Age. Londres: The Architectural Press, 1960.

Cohen, Jean-Louis: Le Corbusier 1887-1965. El lirismo de la arquitectura en la era mecánica. Köln: Taschen, 2004.

Frampton, Kenneth: Le Corbusier. Madrid: Akal, 2002.

Frampton, Kenneth: Historia crítica de la arquitectura moderna. Barcelona: Gustavo Gili, 2002.

Le Corbusier: El arte decorativo de hoy. Carlos Naya Villaverde e Inmaculada Jiménez Caballero (ed.) Maurici Pla Serra (trad.). Pamplona: EUNSA, 2013.

\footnotetext{
${ }^{40}$ Le Corbusier: Precisiones respecto a un estado actual de la arquitectura y del urbanismo, op.cit., p.143.
} 
Le Corbusier: L'art décoratif d'aujourd'hui. Paris: G. Crès \& Cie., 1925.

Le Corbusier: Précisions sur un état présent de l'architecture et de l'urbanisme. París: Les Editions G. Crès et Cie., 1930.

Le Corbusier: Vers une architecture. Paris: G. Crès \& Cie., 1923.

Mang, Karl: History of modern furniture. John William Gabriel (trd.). Londres: Academy Edition, 1979.

McLeod, Mary: Charlotte Perriand. An Art of Living. New York: H.N. Abrams in association with the Architectural League of New York, 2003.

Rüegg, Arthur: Le Corbusier: Meubles et Intérieurs 1905-1965. Zurich: Scheidegger \& Spiess AG, 2012.

Gunther, Sonja: Thonet tubular steel furniture card catalogue. Well-Am-Rhein: Vitra Design Museum, 1989. 